\title{
O FONOAUDIÓLOGO E A ESCOLA - REFLEXÕES ACERCA DA INCLUSÃO ESCOLAR: ESTUDO DE CASO
}

\author{
Speech therapist and school - considerations about the inclusive \\ educational system: case report
}

\author{
Marta Cecília Rabinovitsch Gertel (1), Suzana Magalhães Maia (2)
}

\begin{abstract}
RESUMO
Tema: refletir acerca do papel do fonoaudiólogo na condução das estratégias terapêuticas para a inclusão escolar durante o atendimento de uma criança com Transtorno Global do Desenvolvimento. Procedimentos: pesquisa de natureza clínico-qualitativa desenvolvida por meio de estudo de caso. O material utilizado foi elaborado a partir de registros em forma de relatórios e abrangem os atendimentos à escola, de julho/2002 a novembro/2004. Os recortes no material obtido retratam o percurso seguido ao longo do eixo da história do paciente enfatizando os momentos significativos que geraram desenvolvimento do processo terapêutico fonoaudiológico no que se refere à comunicação oral, integração social no ambiente escolar. Resultados: o paciente envolvido neste estudo frequenta classe de ensino regular e, a partir dos atendimentos fonoaudiológicos, apresentou desenvolvimento significativo em seu comportamento social no ambiente escolar, além de efetivo avanço em sua comunicação oral. Conclusão: considera-se significativo o papel do fonoaudiólogo no atendimento à Escola de modo que terapeuta e educador propiciem o respeito à singularidade de cada criança. Prover condições e estratégias para que a Escola se transforme em um ambiente favorável para o desenvolvimento da criança com necessidades especiais favorece mudanças na constituição de suas relações interpessoais e abre caminho para que se consolide sua inclusão na comunidade.
\end{abstract}

DESCRITORES: Fonoaudiologia; Transtorno Autístico; Educação Especial; Estudos de Casos

\section{INTRODUÇÃO}

A literatura fonoaudiológica é vasta em apresentar referências quanto às atividades do fonoaudiólogo junto à escola. É possível encontrar estudos, pesquisas e relatos que versam sobre diferentes propostas, como: triagem escolar; orientações aos alunos e/ou professores quanto a sua atuação em sala de aula; elaboração de estratégias que favoreçam o processo de aprendizagem dos alunos, por exemplo, durante a alfabetização; capacitação dos educadores na identificação de possíveis alterações de linguagem oral e/ou escrita; entre outros ${ }^{1-6}$.

(1) Fonoaudióloga; Clínica Marta Gertel, São Paulo, SP, Brasil; Doutoranda em Fonoaudiologia na Pontifícia Universidade Católica de São Paulo.

(2) Psicanalista; Docente da Faculdade e do Programa de Estudos Pós-graduados em Fonoaudiologia da Pontifícia Universidade Católica de São Paulo, PUC-SP, São Paulo, SP, Brasil; Doutora pela Universidade São Paulo.

Conflito de interesses: inexistente
Atualmente um tópico que tem merecido destaque nas áreas clínica e educacional diz respeito à inclusão escolar de crianças com necessidades especiais na rede regular de ensino. Encontram-se incluídas na categoria Pessoas com Necessidades Especiais aquelas que apresentam deficiências físicas, visuais, auditivas, síndromes e/ou comprometimentos neurológicos e distúrbios de comportamento ${ }^{7}$.

Seja por conta de exigências legais ou por iniciativa da própria escola, o tema inclusão tem mobilizado os profissionais da área educacional e clínica. Trata-se de um tema polêmico, capaz de gerar desafios e angústias em todos que se encontram envolvidos direta ou indiretamente neste processo, principalmente, por conta de questionamentos quanto às propostas pedagógicas, sociais e afetivas da Escola.

Surge então a necessidade de observar se ela [a escola] está apta a olhar a criança com necessidades especiais para além de suas capacidades 
cognitivas. O que se pretende, então, é criar a possibilidade de mobilização dos professores em seu desejo de discutir e refletir o seu saber pedagógico partindo do princípio que todos têm muito a aprender e é por essa razão que frequentam a escola ${ }^{7-10}$.

É esse olhar diferenciado que permite compreender a escola como um espaço onde todos os que nela se inserem têm um potencial e um papel a desenvolver. Assim, incluir alunos com necessidades especiais deixa de ser visto como resultado de prática específica ou atendimento individualizado somente; ao contrário, passa a ser meta daqueles que acreditam que todos os alunos têm limites que devem ser respeitados ${ }^{8-14}$.

Outrossim, é necessário ter claro que qualquer projeto de inclusão escolar demanda ações intersetoriais, portanto, o fonoaudiólogo pode e deve contribuir para a formação continuada de professores dos sistemas de educação regular e especial, fornecendo apoio, informação e orientação nos processos de inclusão escolar e de envolvimento da comunidade no processo de inclusão social ${ }^{2-4,44-16}$. Como consequência, é nítida a necessidade de mudança na atuação fonoaudiólogica diante destas questões, alterando o paradigma da saúde para o âmbito educacional, inclusive em casos de pacientes com necessidades especiais ${ }^{2-4,16}$.

Essa abordagem clínica e de pesquisa tem procurado seguir preceitos básicos que buscam desvendar maneiras de acolher o paciente, a queixa e a demanda envolvida, compreendendo, assim, por meio da relação terapêutica, necessidades e questionamentos que atravessam a vida da pessoa que chega para atendimento. Nessa perspectiva clínica, procura-se desvendar as necessidades fundamentais de cada pessoa, criança ou adulto, na busca de se constituir como si mesmo ${ }^{2,16}$.

Esse processo [constituir-se] não é finito e é fundamentado por meio das relações sociais que cada pessoa estabelece ao longo de sua vida. Assim é possível compreender a organização social a partir da ideia que cada núcleo familiar faz parte de comunidades que possuem características e tradições culturais próprias transmitidas aos seus filhos e, portanto, fazem parte, também, da sua constituição como sujeito ${ }^{17}$.

Cabe, pois, ao ambiente escolar, como parte da comunidade, um papel suplementar e de ampliação na vida da criança, dando continuidade ao desenvolvimento propiciado pelo ambiente familiar 7-9,16-18. Isto significa destacar este lugar de inscrição social [a escola] e, portanto, com responsabilidades para além do pedagógico: educar refere-se à função realizada pelos adultos tutelares de modo a permitir que a criança ingresse na cultura, tomando um lugar em relação à Lei, aos códigos e aos discursos que nos organizam no social ${ }^{7,18,19}$.

A partir desta perspectiva clínica já é possível encontrar ações fonoaudiológicas junto à Educação que procuram construir, em parceria, práticas mais significativas de ensino e aprendizagem: acolher a diferença, na prática significa perceber que a singularidade não é prerrogativa de pessoas com necessidades especiais ${ }^{2,4,15,16}$.

Tendo em vista as considerações realizadas até aqui sobre inclusão de pessoas com necessidades especiais em escola regular, o objetivo deste artigo é apresentar o relato de um estudo de caso de uma criança com diagnóstico médico de Transtorno Global do Desenvolvimento (TGD) matriculada em escola da rede regular de ensino, onde a ênfase será dada aos aspectos envolvidos nos atendimentos à escola.

\section{APRESENTAÇÃO DO CASO}

Este estudo contou com a participação de um único sujeito, aqui denominado M., sexo masculino, três anos e meio, segundo filho de uma prole de três, ambos os pais com 37 anos. De acordo com os dados apresentados pela mãe, aqui denominada R., a gestação e o parto não apresentaram intercorrêcias e $M$. sempre foi uma criança tranquila. Com um ano e quatro meses, em um acidente doméstico, sofreu uma queimadura séria no braço esquerdo (das costas até o cotovelo). Permaneceu internado no Hospital durante uma semana onde foi submetido à cirurgia para enxerto de pele.

M. foi encaminhado pela escola, em julho de 2002, para uma avaliação fonoaudiológica. Frequentava a classe maternal desde fevereiro de 2002 e a queixa principal da professora era que ele falava pouco.

M. foi atendido pela fonoaudióloga-pesquisadora no consultório de julho de 2002 a novembro de 2004. Além dos atendimentos individuais de $M$. também fez parte da proposta terapêutica o atendimento à família e à escola.

O material utilizado na composição dos dados referentes a esta pesquisa foi elaborado pela pesquisadora ao longo do processo terapêutico a partir de registros em forma de relatórios e abrangem o material clínico obtido nos atendimentos à família e a Escola. Os recortes no material clínico procuraram retratar o percurso seguido ao longo do eixo da história do paciente e os momentos significativos que geraram desdobramentos no desenvolvimento do processo terapêutico fonoaudiológico no que se refere à comunicação oral e integração social no ambiente familiar e escolar. 
Neste artigo os dados obtidos foram restringidos aos relatórios elaborados após os encontros, geralmente mensais, com a Escola. Nestes registros encontram-se descritos as questões elaboradas pela professora e/ou coordenadora, os temas discutidos e as propostas de trabalho com M. em classe. Os aspectos específicos envolvidos nas sessões de atendimento da criança bem como da família não são descritos ou analisados aqui, pois fugiriam ao objetivo deste relato. Entretanto, são mencionados dados gerais do processo terapêutico, desde que façam parte e sejam pertinentes para circunscrever os atendimentos à escola e a evolução clínica do paciente.

Antes de apresentar o relato propriamente dito, é necessário situar alguns aspectos decisivos para a compreensão deste caso. M. é membro de uma família ultra-ortodoxa da Comunidade Judaica de São Paulo. Em geral, judeus ultra-ortodoxos são conhecidos por respeitarem estritamente a Halacha (Leis Religiosas Judaicas) e, dessa maneira, assumirem modelos sócio-culturais que estão cristalizados ao longo de gerações. A manutenção desses padrões sócio-culturais envolve desde a vestimenta, alimentação e língua até a maneira de portar-se em sociedade e a aprendizagem escolar. Para tanto, além de observarem Leis quanto ao comportamento individual, frequentam ambientes sociais que seguem essa mesma linha de conduta e pensamento: escola e sinagoga.

O presente estudo foi aprovado pela Comissão de Ética e Pesquisa da Pontifícia Universidade Católica de São Paulo (PUC-SP) com o número 018/2007; a mãe e o responsável pela escola assinaram o "Termo de Consentimento Informado". O nome do paciente e de seus familiares, bem como da escola foram omitidos, de forma a preservar suas identidades.

\section{RESULTADOS}

Os primeiros encontros com M. foram marcantes: chegava com a mãe, aos berros e pontapés, não falava, não olhava para nada ou ninguém e não passava da sala de espera. Durante o mês de julho de 2002, ao longo de alguns encontros com a mãe, sempre acompanhada do filho, foi possível obter a história de M.: era o segundo filho, pertenciam à comunidade ultra-ortodoxa judaica, a gestação e o parto não apresentaram intercorrências e $\mathrm{M}$. sempre foi uma criança tranquila. Com um ano e quatro meses, começava a andar quando, em um acidente doméstico, sofreu uma queimadura séria no braço esquerdo (das costas até o cotovelo). Permaneceu internado no Hospital durante uma semana onde foi submetido à cirurgia para enxerto de pele. Durante os 6 meses seguintes, por orientação médica, M. não podia brincar no chão, se sujar, molhar ou esbarrar em algo que o machucasse por conta do risco de infecção e rejeição do enxerto de pele.

$R$. assinalou que foi uma época muito difícil: era necessário fazer de tudo para que o filho cumprisse a orientação médica. A partir dessa época $M$. ficou muito agitado, não entendia a palavra não, relutava em aceitar mudanças na sua rotina e, quando contrariado, ficava muito irritado, com sérias crises de birra. Aos 3 anos, não falava nada e não brincava com outras crianças, incluindo irmãos e primos.

Em fevereiro de 2002, M. passou a frequentar a escola [ortodoxa judaica], mas R. não observara grandes evoluções no comportamento do filho: a professora constantemente reclamava que se tratava de uma criança muito difícil; não respeitava ordens e limites, não brincava com outras crianças da classe. Estava sempre sozinho, só fazia o que queria. Quanto à parte pedagógica, ainda de acordo com a mãe, não havia nenhuma queixa por parte da professora. Ao perguntar quais atividades escolares M. gostava e como era sua participação, R. não soube detalhar essas informações, pois não tinha visto nenhuma produção do filho na escola.

Nas palavras de R. o comportamento de M. era o jeito dele e que com o tempo iria melhorar. Também referia que por serem muito religiosos aceitavam a vontade de Deus: cada um é como é. Não havia nenhum comentário, referência ou queixa quanto ao fato de $M$. não manter contato visual, não esboçar qualquer atitude comunicativa ou interesse pelo outro ou pelo ambiente físico. Tudo era creditado ao jeito dele.

A primeira reunião com a professora e a coordenadora pedagógica foi marcada por queixas quanto à dificuldade em lidar com M.: era extremamente agitado, sem limites, não aceitava nenhuma regra, entrava e saía da classe quando queria. Não falava ou emitia qualquer som para se comunicar com a professora e com as crianças; não atendia quando chamado, mesmo se a professora falasse com intensidade de voz elevada. Inicialmente, achavam que ele não escutava, mas observaram que barulhos intensos ou desconhecidos, como de ônibus, sinal de recreio, provocava em M. a reação de colocar as mãos nos ouvidos e gritar. Concluíram, então, que M. não atendia por que não queria. Ainda de acordo com o relato da Escola, M. não se interessava por nenhuma atividade específica, permanecendo, muitas vezes, jogado no chão da sala.

Ao indagar se tinham observado que $M$. não olhava diretamente para algo, que seu olhar parecia atravessar o interlocutor ou os objetos, ambas pareceram extremamente surpresas e afirmaram não ter percebido nada nesse sentido. Comprome- 
teram-se a observar melhor esse tipo de comportamento quando do retorno às aulas [as férias se iniciariam naquela semana] e foi agendada nova reunião quando seriam discutidos os atendimentos fonoaudiológicos iniciais de $\mathrm{M}$.

Nesse primeiro encontro, ficou nítida a angústia vivida pelos profissionais da escola, embora nada fosse verbalizado claramente. A escola parecia querer respostas de como agir com M. para que ele se tornasse um aluno igual aos outros.

No encontro seguinte com a Escola foi observado que depois de determinado ritual religioso - o corte de cabelo - M. havia piorado muito em seu comportamento: ficava agarrado à mochila o tempo todo, deitado no chão, não permitia que ninguém se aproximasse. Questionei se M. tinha alguma noção do que acontecera nessa cerimônia: se havia sido explicado o ritual pelo qual passaria e se já tinha visto outras crianças passarem por esse mesmo evento religioso. Perguntas que não poderiam ser respondidas por M., a escola parecia não ter refletido sobre elas e a família seguia cumprindo os preceitos de sua fé.

Ainda de acordo com o relato da escola, M. não parecia se interessar por muitas atividades: parecia gostar da aula de música, pois não tentava fugir; permanecia no tanque de areia (pegava areia e ficava jogando nas outras crianças e/ou colocando na boca). Quanto às crianças da classe formavam um grupo bem tranquilo e, talvez por serem mais novos que $M$., aceitassem esperar quando a professora saía para buscá-lo. Alguns manifestavam medo, porque $M$. não aceitava ser contrariado, não entendia quando outra criança não queria lhe emprestar algum brinquedo e nestas situações gritava, batia e dava pontapés.

Neste encontro, foram relatadas algumas das estratégias terapêuticas presentes nos atendimentos que, nesta época, exploravam brinquedos e atividades com diferentes tipos de materiais e texturas: bichos de pelúcia, bonecos e brinquedos de madeira, bolas plásticas, de tecido, borracha, entre outros. Por conta disso, professora e coordenadora resolveram que também iriam tentar estimular atividades com diferentes texturas em sala de aula para todo grupo-classe.

Nos encontros subsequentes com a escola - segundo semestre de 2002 - foram relatadas melhoras significativas no comportamento de $\mathrm{M}$.: não fugia mais tantas vezes da sala de aula e, quando saía, assim que chamado, retornava sozinho. Também referiam contato visual esporádico com a professora e que $M$. começava a aceitar toques físicos por parte das crianças da classe e da professora auxiliar. Era possível observar que M. estava começando a interagir com o outro: aten- dia, de alguma maneira, a um pedido [volte para a classe] e estabelecia um processo de comunicação. Ao final do ano a preocupação era quanto à adaptação com a professora da série seguinte.

No início de 2003 a nova professora e coordenadora afirmavam que $\mathrm{M}$. ainda destoava muito do grupo e, por conta disso, não sabiam se ele deveria ser mantido nessa escola [ortodoxa judaica]. Também assinalavam a dificuldade de lidar com ele e os outros alunos, que constantemente manifestavam medo quando M. tinha seus ataques. Algumas vezes, ele batia nas professoras, ainda não respeitava limites ou cumpria as propostas de atividades em aula. Demorava muito para ir para a classe. Quando questionadas se tinham alguma ideia do porquê desse comportamento, responderam que talvez faltasse maior imposição e cobrança de limites por parte dos pais.

Neste momento, a estratégia foi mostrar para ambas como era fundamental que encontrassem um jeito próprio de se comunicar com M.: embora fosse diferente do que esperavam, mais difícil no lidar, não era impossível encontrar um caminho para a constituição dessa relação. De fato, não havia respostas prontas, e o processo seria construído no dia-a-dia para cada um que se relacionasse com $\mathrm{M}$.

Eram nítidos os questionamentos da professora e da coordenadora, pois certamente não era esse tipo de orientação que esperavam ou estavam acostumadas a ouvir de uma fonoaudióloga. Talvez buscassem alguém que concordasse com suas queixas, reconhecesse o quanto $M$. era uma criança difícil e assumisse junto com elas a ideia de mudálo de escola, talvez para uma escola especial.

Neste contexto foi necessário assinalar que, na própria classe, cada criança era diferente, que com cada uma havia uma maneira toda própria de lidar, de se achegar, de tocar. Com M. não seria diferente, só precisavam confiar que podiam encontrar esse caminho. Indagada sobre qual seria este caminho assinalei que talvez bastasse, naquele momento, iniciar com um olhar para além do que ele não fazia.

Nos encontros seguintes, coordenadora e professora já referiam observar melhoras no comportamento geral de M.: respeitava mais os limites da rotina diária da classe; estava menos agressivo; gostava de ficar abrindo e fechando gavetas e a porta do armário; às vezes permanecia deitado no chão, empurrando um carrinho de brinquedo. Em suas palavras não demonstrava nenhum aproveitamento pedagógico do período escolar, principalmente porque não participava das atividades coletivas.

A partir desse dizer a estratégia foi refletir com ambas o que seria aproveitamento pedagógico para uma criança como $\mathrm{M}$. $\mathrm{O}$ respeito à rotina de 
classe não é um comportamento pedagógico? Será que estar menos agressivo ou aceitar alguma regra social da classe não era tão importante quanto recortar um quadrado e colar no espaço correto? Novamente, nossa meta era destacar que, se as perguntas eram diferentes para M., não seria possível esperar respostas pré-concebidas.

Na reunião final de 2003 foi relatado que M. iniciara a formação de vínculos com outras pessoas além da professora e das crianças da classe: a servente, o porteiro e professoras de outras classes. Já atendia ordens simples como, por exemplo, "vá lavar as mãos; vamos para o tanque [de areia]". Mais importante é que consideravam que $M$. deveria permanecer nesta escola, pois entendiam que a questão religiosa era muito importante para os pais e, consequentemente para $\mathrm{M}$. também.

Em 2004 haveria mudanças de unidade da escola e de coordenação, portanto, a professora e coordenadora sugerirão reuniões com a nova equipe antes do ano letivo.Também disponibilizaram a professora auxiliar de 2003 para permanecer durante o mês de fevereiro de 2004 na nova classe, no intuito de favorecer a adaptação de M. Era gratificante: a escola talvez ainda não tivesse se dado conta, mas já tinha respostas para suas próprias perguntas, sem buscar outros pareceres.

Em janeiro de 2004, na reunião com a nova equipe escolar, foi relatado um pouco do processo de desenvolvimento de $M$. até então. Novamente, era possível observar a nova coordenadora e professora repletas de perguntas e busca de respostas prontas sobre onde, como e quando agir. Outra vez apresentava-se a necessidade de garantir o espaço para as reflexões e angústias de profissionais que questionavam se sua formação poderia dar conta da criança que chegava.

Em fins de fevereiro de 2004, nova reunião com a escola e um fato emocionante: a adaptação de M. no novo espaço fora surpreendente. A auxiliar ficou só na primeira semana de aula, pois M. estava interagindo bem com a nova professora. Relataram que ele não apresentou dificuldades em explorar e conhecer o novo ambiente físico da escola: prédio, classe, banheiro etc. A única atitude que chamou atenção foi que ele sempre queria ficar no computador da sala da coordenadora e era muito difícil tirá-lo de lá.

Ao longo de 2004, os profissionais da escola relatavam que $M$. já não ficava tanto tempo no computador, só um pouco no final do horário de almoço, mas quando a professora chamava para voltar para a classe, ele aceitava prontamente e acompanhava os colegas. Nas refeições, sempre comia arroz, feijão e água, não aceitava experimentar outros alimentos nem suco. Continuava com dificuldades para aceitar atividades que envolviam molhar-se, como, por exemplo, lavar as mãos, usar tinta e argila. Fazia uso de alguns gestos indicativos e representativos (apontar, não) com a professora e com as outras crianças quando queria se comunicar. Na aula de ginástica já participava de algumas atividades: corria e jogava bola, sorrindo muito quando a jogava bem para o alto.

Em uma atividade externa [passeio para um sítio] as professoras acharam que foi muito difícil para M., talvez porque o espaço era amplo e muito diferente da escola. Em suas palavras M. parecia estar perdido, como se não soubesse como deveria agir. Entretanto, foi muito significativo observar como elas, professoras e coordenadora, relatavam os acontecimentos com sensibilidade para perceber o desconforto de $\mathrm{M}$. sem pedir receitas de como agir ou como modificar as atitudes dele. Seu lugar na classe já era uma conquista.

Na última reunião de 2004, a professora relatou que M. havia cismado com algumas crianças da classe, e estava mais agressivo com elas. Por sua vez, essas crianças passaram a expressar medo de M., e algumas não queriam brincar mais com ele ou ficar ao seu lado. A professora vinha desenvolvendo um trabalho com o grupo para que respeitassem os amigos e as diferenças no modo de ser e agir de cada um.

M. já atendia algumas ordens para realizar atividades em sala de aula, mesmo quando fazia as coisas do jeito dele, por exemplo, para pintar, recortar ou guardar o material escolar. Respeitava mais os limites e os horários programados pela professora para os trabalhos em classe e não ficava mais tanto tempo deitado no chão.

Ainda não aceitava experimentar nada novo no almoço, mantendo sempre a dieta do arroz e feijão. Era interessante observar como cada vez mais a professora procurava soluções para resolver seus problemas do dia-a-dia com autonomia e envolvendo o grupo classe. M. era considerado parte desse grupo e passara a ser respeitado como tal.

\section{DISCUSSÃO}

O processo terapêutico apresentado neste estudo de caso direcionou reflexões acerca da constituição de cada indivíduo em seus aspectos físico, emocional e social. Ao propiciar um olhar diferenciado e único para o paciente e o ambiente a que pertence [família, escola, comunidade] tornase possível acolher a queixa e a demanda de cada caso ${ }^{2,16}$.

No caso de M., compreender sua história e sua herança cultural, bem como a comunidade a que pertence, fez parte das estratégias terapêuticas, de 
modo que o fazer clínico favoreceu a constituição do paciente. Assumir essa postura ética durante o atendimento de uma pessoa, refletindo sobre suas questões a partir de suas raízes, levando em conta a realidade da família, da escola e da comunidade onde se encontra inserido aquele núcleo social, a etnia, a cultura e a ética passam a ser compreendidas como fundantes do ser humano e, portanto, como lugar de enraizamento e existência ${ }^{16-18}$.

Como ficou evidente no caso de M., que frequentava uma escola da comunidade judaica que ainda não havia se posicionado frente à questão da inclusão de crianças com necessidades especiais, esse processo gera desafios e angústias em todos os envolvidos, sejam eles professores, coordenadores e/ou funcionários em geral. Esses sentimentos decorrem, principalmente, do estar diante de algo novo, de alguém que demanda reflexões e questionamentos quanto às propostas pedagógicas, sociais e afetivas da escola ${ }^{3,8-14}$.

Acolher as angústias e criar um espaço para a reflexão e busca de soluções pode e deve fazer parte do atendimento fonoaudiológico à Escola, contribuindo para a constituição do lugar da criança com necessidade especial na classe, viabilizando sua socialização e, portanto, sua constituição como sujeito. Neste relato também foi assinalada a importância da criança [com necessidades especiais] ser considerada uma parceira que contribui efetivamente para o grupo-classe. Cabe ao professor, e aos fonoaudiólogos, desvendar qual é essa contribuição ${ }^{2-4,15,16}$.

Cabe destacar aqui a importância do fonoaudiólogo criar a possibilidade de escuta dos professores que lidam com crianças ditas difíceis de modo a possibilitar a mobilização do desejo de discutir e pôr em questão seu saber pedagógico ${ }^{2,4,16}$. Nesse sentido, torna-se fundamental compreender a angústia da escola e sua busca por uma receita de como agir com o aluno que se apresenta de uma maneira diferente do esperado, cabendo ao terapeuta acolher essas questões e ao mesmo tempo, respeitar a singularidade e o ritmo da equipe escolar, de modo a constituir o lugar deste aluno como parte do grupoclasse como ocorria no caso aqui em foco ${ }^{16}$.

Neste sentido, o fonoaudiólogo pode assumir o papel de mediador entre a criança e a escola, em uma posição diferente: não como alguém que detém a receita ou a fórmula do que fazer com a criança com necessidade especial, mas, ao contrário, como parte de um ambiente humano onde se cria a oportunidade de um devir. Ao adotar essa postura de reflexão e constituição, tem-se a oportunidade de respaldar a prática clínica nas vivências singulares de cada paciente ${ }^{2,16}$.

Ao mesmo tempo o trabalho do fonoaudiólogo junto à Educação caminha na busca por construir, em parceria, prática mais significativa de ensino e aprendizagem além de ampliar seus parâmetros para decidir a adaptação do conteúdo pedagógico a ser trabalhado com cada aluno, inclusive com os alunos com necessidades especiais ${ }^{2-4,15,16}$.

Por conseguinte, acolher a diferença é reconhecer a natureza do desenvolvimento humano, que é, por excelência, singular. A partir dessa concepção, o educador é capaz de propiciar situações de comunicação contextualizadas em um ambiente favorável e passa a compreender que incluir é mais do que integrar. Comprometer-se com o processo de inclusão não significa igualar os diferentes, mas respeitar as possibilidades e as dificuldades que são constituintes de cada ser humano $2,4,9-11,14-16$.

\section{CONCLUSÃO}

O propósito deste artigo foi assinalar, a partir de um estudo de caso, o papel do fonoaudiólogo no atendimento à Escola de modo que terapeuta e educador propiciem o respeito à singularidade de cada criança. Prover condições e estratégias para que a Escola se transforme em um ambiente favorável para o desenvolvimento da criança com necessidades especiais favorece mudanças na constituição de suas relações interpessoais e abre caminho para que se consolide sua inclusão na comunidade.

Dessa maneira, o fonoaudiólogo pode e deve contribuir para a formação continuada de professores dos sistemas de educação regular e especial, de modo que a Escola possa ser compreendida como um espaço onde todos os que nela se inserem têm um potencial e um papel a desenvolver. Assim, incluir alunos com necessidades especiais deixa de ser visto como resultado de prática específica ou atendimento individualizado somente; ao contrário, passa a ser meta daqueles que acreditam que todos os alunos têm limites que devem ser respeitados.

Neste sentido fica assinalada aqui a necessidade de novos estudos e pesquisas direcionadas à família e à escola dos pacientes no sentido de consolidar o lugar do fonoaudiólogo no atendimento do ambiente humano a que pertence aquele que chega à clínica fonoaudiológica. 


\begin{abstract}
Background: to reflect and discuss about the role of a speech therapist in therapeutical strategies for a child with Pervasive Development Disorder in the inclusive educational system. Procedures: this is a case report research of a child with Pervasive Development Disorder. The clips of the clinical material includes written reports, obtained in appointments with the school, showing the course followed during the patient's history, giving emphasis to the significant moments that generated the development of the therapeutical process related to oral communication and interaction with his group-class [teachers and students]. Results: the patient involved in this study attends a regular school class and due to the therapeutical interventions showed a significant development in relation to his group-class [teachers and students] and social behavior, besides the effective improvements in his oral communication. Conclusions: in our understanding the role of the speech therapist is significant in leading with the school in order to provide a favorable physical and emotional environment that should respect the singularity and the development of each child. Therapeutical targets can be focused on the purpose that School need changes in order to promote a favorable environment for children with special needs. These situations make the difference as for to consolidate the social and community inclusion.
\end{abstract}

KEYWORDS: Speech, Language, Hearing Sciences; Autistic Disorder; Education, Special; Case Studies

\section{REFERÊNCIAS}

1. Maranhão PCS, Pinto SMPC, Pedruzzi CM. Fonoaudiologia e educação infantil: uma parceria necessária. Rev. CEFAC. 2009; 11(1):59-66. http:// dx.doi.org/10.1590/S1516-18462008005000006

2. Serapompa MT, Maia SM. Acolhimento e inclusão: da clínica ao acompanhamento escolar de um sujeito com Síndrome de Down. Dist Comun. 2006; 18(3):313-22.

3. Rios NVF, Novaes BCAC. O processo de inclusão de crianças com deficiência auditiva na escola regular: vivências de professores. Rev. Bras. Ed. Esp. 2009; 15(1):81-98.

4. Ramos AS, Alves LM. A fonoaudiologia na relação entre escolas regulares de ensino fundamental e escolas de educação especial no processo de inclusão. Rev. Bras. Educ. Espec. 2008; 14(2):235-50.

5. Colella-Santos MF, Bragato GR, Martins PMF, Dias AB. Triagem auditiva em escolares de 5 a 10 anos. Rev. CEFAC. 2009; 11(4):páginas. http:// dx.doi.org/ 10.1590/S1516-18462009005000037

6. Penteado RZ, Camargo AMD, Rodrigues CF, Silva CR, Rossi D, Silva JTC, et al. Vivência de voz com crianças: análise do processo educativo em saúde vocal. Dist Comun. 2007; 19(2):237-46.

7. American Psychiatry Association (APA). Manual Diagnóstico e Estatístico de Transtornos Mentais (DSM-IV). 4. ed. Porto Alegre: Artes Médicas; 1995.
8. Bastos MB. Impasses vividos pela professora na inclusão escolar. Estilos Clín. 2001; 6(11):47-55.

9. Oliveira AAS, Leite LP. Construção de um sistema educacional inclusivo: um desafio políticopedagógico. Ensaio: Aval Pol Publ Educ. 2007; 15(57):511-24.

10. Mesquita RB, Landim FLP, Collares PM, Luna CG. Análise de redes sociais informais: aplicação na realidade da escola inclusiva. Interface Comun Saúde Educ. 2008; 12(26):549-62.

11. D'Agua SVNL. Inclusão de alunos com necessidades educacionais na rede regular de ensino: análise da experiência da diretoria de ensino regional de Franca: desafios e possibilidades [tese]. São Paulo (SP): Pontifícia Universidade Católica de São Paulo; 2007.

12. Silva SC, Aranha MSF. Interação entre professora e alunos em salas de aula com proposta pedagógica de educação inclusiva. Rev. Bras. Educ. Esp. 2005; 11(3):373-94.

13. Sant'ana IM. Educação inclusiva: concepções de professores e diretores. Psicol Estud. 2005; 10(2):227-34.

14. Ferreira MEC. O enigma da inclusão: das intenções às práticas pedagógicas. Educ Pesq. 2007; 33(3):543-60.

15. Trenche MCB, Baliero CR. Fonoaudiologia e inclusão social. In: Ferreira LP, Befi-Lopes DM, Limongi SCO, organizadores. Tratado de fonoaudiologia. São Paulo: Rocca; 2005. p. 725-31. 
16. Gertel MCR. O papel do fonoaudiólogo na rede de relações sociais de uma criança com Transtorno Global do Desenvolvimento: estudo de caso [dissertação]. São Paulo (SP): Pontifícia Universidade Católica de São Paulo; 2008.

17. Safra G. A po-ética na clínica contemporânea. São Paulo: Idéias e Letras; 2004.
18. Winnicott DW. A mãe, a professora e as necessidades da criança. In: Winnicott DW. A criança e o seu mundo. Rio de Janeiro: L.T.C.; 1982. p. 214-24.

19. Martins VAC. Espaço escolar como herdeiro das funções parentais. Estilos Clin. 2001; 6(11):27-32.

Endereço para correspondência:

Marta Cecília Rabinovitsch Gertel

Rua Albuquerque Lins, 848/132

Higienópolis - SP

CEP: 01230-000

E-mail: martagertel@uol.com.br 